\title{
Diabetes and premature death
}

After overcoming, in the last century, the obstacle of a short life expectancy of about third years, humanity was faced with an amplitude of challenges associated to the several genetic vulnerabilities linked to lifestyle changes and aging. At the center of these dis-adjustments, is the type II diabetes mellitus (DM II). Despite the persistence of the unbalance in the calorie intake and lack of physical activity, according to estimates by the International Diabetes Foundation (IDF), the expansion curve for the incidence of DM2 shows a slight deceleration, at a ratio of $0.5 \%$. However, the condition has already affected $7 \%$ of the world population of adults and is the cause of around $10 \%$ of all deaths ${ }^{1-8}$. Thus, a diagnosis of DM2 means a decrease of up to two decades in life expectancy, according to the type and prematurity of the DM2 found $^{9}$. Besides, morbidities such as amaurosis, dementia, neuropathies, and chronic kidney disease make this condition a topic of absolute urgency and relevancy.

Since it started being recorded, cardiovascular disease (CV) has been responsible for $80 \%$ of deaths of individuals with DM $2^{10}$. Thus, several observational and interventional studies sought to identify the primary mediators for $\mathrm{CV}$ risk in individuals with
DM2 in order to improve the risk estimate and intervene slowing down the high mortality. Blood glucose control was the most significant intervention for reducing mortality. However, the intensive control of blood glucose levels to values close to those of healthy individuals did not present any benefits ${ }^{11}$ and, in one of the studies, was even associated with an increase in mortality (+2.9 deaths for every 1,000 patients/ year $^{12}$. Likewise, the control of the arterial pressure (-3.2 deaths for every 1,000 patients/year per $10 \mathrm{~mm}$ $\mathrm{Hg})^{13}$ and the LDL cholesterol (-2.1 deaths for every $1,000$ patients/year per $39 \mathrm{mg} / \mathrm{dL})^{14}$ were critical elements in this strategy for risk control. Similarly to the blood glucose control, the intensification of these interventions did not present any benefits regarding survival $^{15,16}$. In addition, anti-diabetes therapies were associated with an increase in the incidence of cardiovascular diseases ${ }^{17}$.

The high residual mortality and the uncertainty of the CV effects of the therapies led to a demand for new treatments systematically tested by cardiovascular safety studies. Despite having been outlined to asses safety, two classes of anti-diabetic medication have shown a reduction in mortality regardless of the effect on glucose: sodium-glucose cotransport- 
er-2 (SGLT-2i) inhibitors (-9 deaths for every 1,000 patients/year) ${ }^{18}$ and Glucagon-like peptide-1 (GLP-1) agonists (-4 deaths for every 1,000 patients/year) ${ }^{19}$. Thus, over the last five years, not only the reduction of the possibility of prolonging the life of DM2 patients was demonstrated, but it was done as an addi-

\section{REFERENCES:}

1. IDF Diabetes Atlas. 1st ed. ed. Brussels, Belgium: International Diabetes Federation; 2000.

2. IDF Diabetes Atlas. 2nd edition ed. Brussels, Belgium: International Diabetes Federation; 2003

3. IDF Diabetes Atlas. 3rd edition ed. Brussels, Belgium: International Diabetes Federation; 2006.

4. IDF Diabetes Atlas. 4th edition ed. Brussels, Belgium: International Diabetes Federation; 2009.

5. IDF Diabetes Atlas. 5th edition ed. Brussels, Belgium: International Diabetes Federation; 2011.

6. IDF Diabetes Atlas. 6th edition ed. Brussels, Belgium: International Diabetes Federation; 2013 .

7. IDF Diabetes Atlas. 7th edition ed. Brussels, Belgium: International Diabetes Federation; 2015.

8. Bertolami A, de Lima-Junior JC, Cintra RM, et al. Adiponectin concentration data improve the estimation of atherosclerotic risk in normal and in overweight subjects. Clin Endocrinol (Oxf) 2018;88:388-96.

9. Emerging Risk Factors $C$, Di Angelantonio E, Kaptoge $S$, et al. Association of Cardiometabolic Multimorbidity With Mortality. JAMA 2015;314:52-60.

10. Wright AK, Kontopantelis E, Emsley R, et al. Life Expectancy and Cause-Specific Mortality in Type 2 Diabetes: A Population-Based Cohort Study Quantifying Relationships in Ethnic Subgroups. Diabetes Care 2017;40:338-45.

11. Fang HI, Zhou YH, Tian Y|, Du HY, Sun YX, Zhong LY. Effects of intensive glucose lowering in the treatment of type 2 diabetes mellitus on cardio- tional effect to the control of traditional risk factors.

In this edition, we bring a selection of original studies and reviews dedicated to DM2 grouped with the purpose of emphasizing the enormous mortality of this disease, but also to the substantial advancements achieved for its control. vascular outcomes: A meta-analysis of data from 58,160 patients in 13 randomized controlled trials. Int J Cardiol 2016;218:50-8.

12. Action to Control Cardiovascular Risk in Diabetes Study G, Gerstein HC, Miller ME, et al. Effects of intensive glucose lowering in type 2 diabetes. $N$ Engl J Med 2008;358:2545-59.

13. Emdin CA, Rahimi $K$, Neal B, Callender T, Perkovic V, Patel A. Blood pressure lowering in type 2 diabetes: a systematic review and meta-analysis. JAMA 2015;313:603-15.

14. Cholesterol Treatment Trialists C, Kearney PM, Blackwell L, et al. Efficacy of cholesterol-lowering therapy in 18,686 people with diabetes in 14 randomized trials of statins: a meta-analysis. Lancet 2008;371:117-25.

15. Brouwer TF, Vehmeijer IT, Kalkman DN, et al. Intensive Blood Pressure Lowering in Patients With and Patients Without Type 2 Diabetes: A Pooled Analysis From Two Randomized Trials. Diabetes Care 2018;41:1142-8.

16. Sabatine MS, Leiter LA, Wiviott SD, et al. Cardiovascular safety and efficacy of the PCSK9 inhibitor evolocumab in patients with and without diabetes and the effect of evolocumab on glycaemia and risk of new-onset diabetes: a prespecified analysis of the FOURIER randomised controlled trial. Lancet Diabetes Endocrinol 2017;5:941-50.

17. Nissen SE, Wolski K. Effect of rosiglitazone on the risk of myocardial infarction and death from cardiovascular causes. N Engl J Med 2007;356:245771.

18. Zinman B, Wanner C, Lachin JM, et al. Empagliflozin, Cardiovascular Outcomes, and Mortality in Type 2 Diabetes. N Engl J Med 2015;373:2117-28.

19. Marso SP, Daniels GH, Brown-Frandsen K, et al. Liraglutide and Cardiovascular Outcomes in Type 2 Diabetes. N Engl | Med 2016;375:311-22. 